CESIS Electronic Working Paper Series

Paper No. 436

\title{
Innovation Strategies Combining Internal and External Knowledge
}

\section{Börje Johansson}

Hans Lööf

April, 2016 


\title{
Innovation Strategies Combining Internal and External Knowledge
}

\author{
Börje Johansson ${ }^{1} \&$ Hans Lööf ${ }^{2}$
}

\begin{abstract}
We introduce a framework for analyzing renewal efforts of firms with distinct categories of innovation and adoption strategies, comprising a firm's development off its internal knowledge, its access to local knowledge sources and its access to global knowledge sources. A fundamentall aspect is the formation and maintenance of the firm's renewal capabilities. In this way the analysis provide an explanation of remaining heterogeneity among firms belonging to the same industry such that one group performs above average for long sequences of time, whereas others continue to pperform below average. The analysis applies Swedish data when presenting alternative approaches to provide empirical support in favour of the outlined model of how long-run firm performance associates with each firm's sustained efforts to combine interal and external knowledge sources.
\end{abstract}

JEL Classification Codes: F21; O31; O3; R11

Keywords: Adoption; Innovation; Innovation outcome; Knowledge sources and networks; Combined internal and external knowledge

\footnotetext{
${ }^{1}$ Jönköping International Business School (JIBS), Centre of Excellence for Science and Innovation Studies (CESIS)\& Royal Institute of Technology(KTH). E-mail:borje.johansson@jibs.hj.se

${ }^{2}$ Centre of Excellence for Science and Innovation Studies (CESIS)\& Royal Institute of Technology(KTH).

E-mail:hans.loof@indek.kth.se
} 


\section{INTRODUCTION}

Economists' recognition of innovation and technology is often ascribed to the contribution of Schumpeter's (1934), spelled out in "The Theory of Economic Development", conveying the message that without innovations the market economy would settle in a stationary Walrasian equilibrium. Precisely the same message was delivered by Solow (1957), declaring that in equilibrium GDP per capita of a competitive economy will grow only to the extent that technology improves over time. A novel element was that the Solow model prescribed a way to calculate the size of the yearly change of technology.

In the Solow perception of the economy, knowledge improvements drive the annual increase of the productivity of the representative (average) firm, and hence there are no questions asked about the distribution of productivity across firms in the same industry. The Schumpeter perception is quite different by focusing on how individual firms in an industry develop innovation ideas that improves their productivity relative to the average firm in the same industry. This implies that at any point in time, we should expect heterogeneity such that some firms are clearly superior to the average, whereas others are inferior.

The Schumpeter view incorporates a second dynamic phenomenon that is strongly associated with innovations. This additional factor may be termed adoption and considers the opportunity of other firms to imitate and get inspired to catch up with those firms that have reached a higher productivity level, reflecting the reward associated with innovation efforts. This reward erodes as other firms adopt the same or a similar solution as the initial innovation, a view that remains a basic perception of innovation adjustment processes (Cefis and Cicarelli, 2005). Adoption processes of this kind work against and reduce heterogeneity. In the following presentation, the analysis will rely on numerous observations that heterogeneity is a generic feature of firms in an industry or firms that supply product varieties belonging to the same product group.

The observations to which we will refer cover differences between firms with regard to variables such as size, internal knowledge resources, productivity and profitability, market extension, output prices. Thus, differences are present for both inputs and outputs; in fact, differences are present in all dimensions that can be observed (Dosi and Nelson, 2010). In view of this we suggest that firm differentials to a large extent are caused by the innovation 
and adoption strategy of each firm. Given that the innovative and renewal behavior of most firms remains unchanged over time, then this is consistent with observations saying that productivity and other performance differentials remain approximately unchanged over fairly long sequences of years (Geroski, 1998). Our ambition is to examine the idea that firm performance differentials are generated by knowledge differences across the same firms.

How should we conceive the notion of a firm's innovation strategy, and should it be labeled "innovation strategy"? A major element in a pro-active strategy of an innovating firm is its plans to build up renewal capabilities and maintain a resource that includes renewal skills of employees, routines for orchestration of $R \& D$ and efforts to access external knowledge. Firm capabilities also include links to other actors for knowledge accession and collaboration (Andersson et.al. 2012). In line with these thoughts the presentation will structure the analysis of innovation strategy to concern a firm's development of its (i) internal knowledge, (ii) access to local knowledge sources, and (iii) access to global knowledge sources. Such a strategy comprises both innovation and adoption activities.

In the framework for characterizing, classifying and analyzing innovation strategies of firms, we claim that a firm's knowledge should be divided into two categories, namely capabilities and technical solutions, where the latter have broad Schumpeterian interpretations and include product attributes, production processes and routines, and interaction approaches vis-à-vis input suppliers and customers. Capabilities refer to a firm's capacity and skills with regard to adjusting, developing and adopting its "library" of technical solutions.

A major message from the presentation is that firm capabilities differentiate firms. They take time to develop, require recurrent maintenance, and they are difficult and costly to imitate (Teece, 2010). Compared to the costs of replicating technical solutions of other firms, the costs of adopting the capability of another firm may appear as prohibitively high. Thus, differences in firms' capabilities form a candidate for explaining remaining heterogeneity among firms. In view of this, the following presentation suggest ways along which this issue can be researched. 


\section{LITERATURE ON KNOWLEDGE OF THE INNOVATING FIRM}

\subsection{Innovation and Adoption Efforts}

Innovation is about change and hence requires a temporal setting, where the analysis has to recognize that the development of the novelty takes time and that performance effects may be delayed. Novelty is also a temporal distinction and the literature distinguishes between novelties that are new to the firm, new to a separate market, new to an industry, and new in a global context. Obviously, something that is new to a firm may be the outcome of product or process design that has been adopted from an innovation made by another firm, belonging to another industry or operating in other geographical markets. We will use this as a first indication that innovation and adoption activities are overlapping and in this sense similar processes. The two phenomena belong to the class of firm renewal processes.

Renewal processes comprise a firm's change of product attributes and portfolio of product varieties, processes and routines, links to customer markets, patenting, and recruitment of employees. The effects of those processes can be identified by means of both direct and indirect observations. As an example of direct observations we will consider statistics that reveal entry and exit of product varieties in a firm's output mix, patent applications, grated patents etc. The second type of observables includes both unobserved fixed effects captured in econometric models and firm performance. Hall (2011) suggests productivity growth as an innovation indicator.

Following an extensive survey by Cohen (2010), one may argue that innovation is identified when productivity can be associated with $R \& D$ efforts, the latter being a sub category of renewal efforts. The identification relies on a coupling of efforts and performance effects. Cohen shows that a considerable amount of empirical research has been devoted to investigating two phenomena: (i) the size of the firm and (ii) the market structure. A first conclusion is that one cannot reject the hypothesis that R\&D is proportional to size. A second conclusion is that both firm size and market structure are rather consequences of innovation activities, such that firms that grow to become large do that by developing many product varieties and by arranging destination links to many alternative markets (Andersson and Johansson, 2012). 
In the context of market structure, Sutton (1991) observes that the presence of upfront sunk costs associated with long-term $\mathrm{R} \& \mathrm{D}$ investments imply that there will be barriers to entry into and exit from the group of innovating firms in an industry. Moreover, as argued by Aghion et al. (2005) and Antonelli and Scellato (2011), Schumpeterian rivalry drives firms to innovate in a persistent way, and this gives rise to a twofold effect. First, a higher profitability facilitates the funding of renewal efforts. Second, large margins indicate barriers to entry and associated market power, which in turn can lower the incentives to exercise persistent innovation efforts.

A major part of Cohen's review focuses on the association between firms' innovation activity and their individual characteristics. In that context it is vital to carefully identify characteristics that remain approximately unchanged for periods of several years. Only such characteristics can be meaningfully employed to predict future innovation activity. Keeping this in mind, we consider that Cohen structures the possible firm characteristics into (i) cash flow, (ii) R\&D capabilities and internal knowledge resources, and (iii) external knowledge sources.

Cash flow as a determinant of a firm's renewal effort has received much attention over many decades (Antonelli, 1989; Hall, 2002) There is evidence in favor of an association between variation in cash flow and variation in R\&D efforts (Martinsson and Lööf, 2013). The intuition behind this finding is that when cash-flow wanes, firms tend to refrain from innovation which, by some stochastic probability, only stands to generate cash-flow sometime in the future. However, Martinsson and Lööf (2013) suggest that equity capital is a more crucial determinant for sustained renewal efforts. Firms with a large equity to total-assets ratio have a better capacity to maintain a smooth innovation profile through time.

Thus, it is evident that cash flow is questionable if we are looking for a slowly changing characteristic of a firm, although it might reflect firm size, while also indicating returns to innovation efforts in the past. R\&D capabilities and renewal capacities in general, on the other hand, may be classified as a slowly changing property of a firm, developing as a consequence of collecting experiences in the firm's process of renewal efforts. This form of renewal capacity comprises in a diffuse way both knowledge production and absorption of knowledge flows. 
Consider that the above picture describes how differences in firms' renewal capabilities affect their $R \& D$ and other renewal expenditures, as well as their size. Then we might also contemplate that a firm's diversification is correlated with renewal capacity and internal knowledge (MacDonald, 1985; Montgomery and Hariharan, 1991). In such a perspective we place the driving force with the slowly changing internal knowledge of the firm. However, this is not where we want to stop. Our ambition is to widen the perspective and consider the external knowledge sources of the firm, and to suggest that firm capabilities also include knowledge about how to access external knowledge and absorb knowledge flows through links for collaboration and knowledge transfer.

Issues of knowledge sources outside the firm brings additional aspects such as a firm's proximity and links to university research as well as commercial knowledge providers (Stephan, 2002). It also brings to the forefront knowledge links between firms belonging to the same company group (Johansson and Lööf, 2008). In particular, external knowledge flows can be associated with the presence of agglomeration economies of the type related to urbanization economies as suggested by Jacobs (1969, 1984), and more generally to the geography of innovation (Feldman and Kogler 2010).

\subsection{Transitory and Lasting Performance Advantages}

Dividing a firm's R\&D expenditures by its value added provides a means to control for firm size. This normalization procedure gives us the measure R\&D intensity for each firm, and a large share of the variance in this intensity can be explained by fixed firm effects, indicating strong heterogeneity in firms' innovative behavior (Cohen, 2010). This observation leads to the temporal question: do some of the firms in a population within a given industry continue to have a high R\&D intensity over a series of years, and do other firms engage in R\&D efforts only occasionally or not at all?

The question asked is vital according to the collection of views presented in the introductory section with reference to Schumpeter and Solow as well as to endogenous growth models (Romer, 1990); productivity is augmented by renewal activities, including R\&D and knowledge accession efforts. A follow up issue is how the productivity gains unfold across firms and along time. The Schumpeter-Solow model perspective is that firms that manage to adopt and develop new solutions can gain an advantage over other firms, for example in the form of above average productivity, and thereby they represent best practice solutions. This 
advantage may be interpreted as a temporary monopoly profit or as an economic rent, based on knowledge that is not available to competitors. Advantages of this kind are considered as transitory, which means that the economic rent of an adoptor/innovator erodes as other firms strive to adjust their routines and output attributes towards the best practice.

The idea that other firms respond to successful novelties developed by competitors is a fundamental property that economists refer to when arguing in favor of market mechanisms, resembling various versions of Darwinian adjustments, such as replicator dynamics (VegaRedondo, 2003). Given this, how can this conclusion be reconciled with observations saying that lasting differences in firm characteristics and performance represent a generic phenomenon, which we cannot avoid to observe? Before answers to this question are suggested in sections 3-5, we will dwell on the rigidity of firms' heterogeneity.

Firms in the same industry or firms supplying product varieties belonging to the same product group have as a rule heterogeneous characteristics and display different performance in terms of productivity, profitability or growth, and they differ in their R\&D and innovation efforts. In established microeconomic theory such differences are predicted to vanish over time, based on the argument that only the best practice can survive. Empirical observations do not support this view (Dosi and Nelson 2010). To a large extent, inter-firm differences remain over long time sequences.

Differences between firms in a given industry (or group of industries) may be identified for a panel of firm observations over time. Such a panel will contain differences for each individual firm at different points in time as well as differences between firms that remain basically unchanged along time. We may then, with reference to Geroski (1999), calculate the total variance for a performance variable like value added or gross profit per employee, and then in a second step determine how much of the variance is due to the variation between years for each individual firm, referred to as within variance. The remaining variance can then be conceived as a persistent difference between firms, referred to as between variance. This between variance is typically 3-4 times larger than the within variance (Andersson et al 2012). Such observations demonstrate heterogeneity among firms in most industries, while at the same time showing that differences between firms persist over time (Peters, 2009; Antonelli etl, 2012). 
Figure 1 provides a picture of the labor productivity 2006 in an industry supplying differentiated products, based on Swedish data. The horizontal axis measures the cumulative output from firms in the sector when firms are ordered according to descending productivity. The figure illustrates how the quartile with the highest productivity has a productivity level which is 3-4 times as large as the level in lowest quartile. Such performance differences provide a strong incentive to examine firm characteristics when assessing performance. Among such characteristics the literature has considered firms' behavior with regard to efforts to innovate and to adopt new technology developed by other firms. The first aspect associates with the process of generating innovation and the second with diffusion in the form of commercial transfers and spillovers.

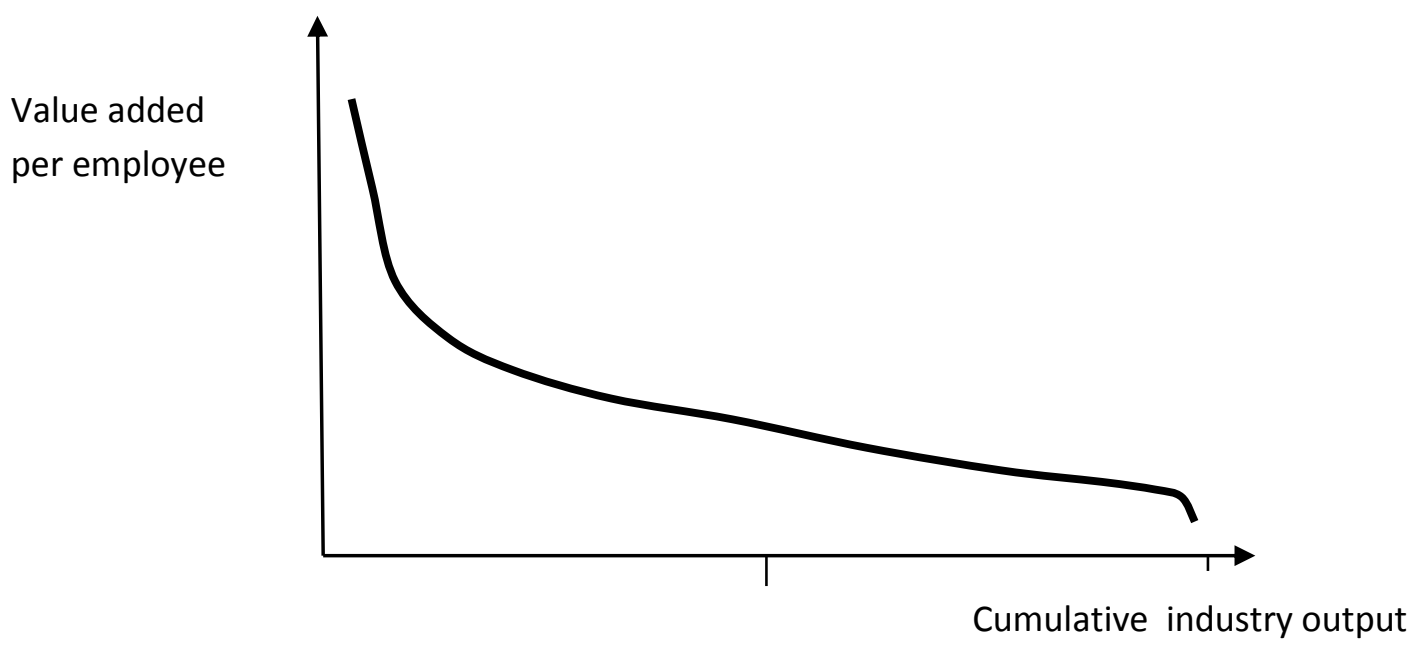

Figure 1: Labour productivity cross-tabulated against output of firms in an industry in productivity-descending order (Johansson, 2013)

The performance distribution illustrated in Figure 1 was discussed early by Heckscher (1918), and from this he could derive the Heckscher cost curve (Johansson, 1991). Hotelling (1932) argued that the cumulative distribution in the figure reflects a bell-shaped frequency distribution and derived an industry supply curve, claiming that the distribution properties can be considered as generic. The diagram in the figure is also related to what is labeled Salter diagrams (Salter, 1960). The intriguing thing with the kind of productivity distributions illustrated in Figuure 1 is that their shape remains invariant over time and corresponds to a persistent ranking of firms' relative productivity.

\subsection{Classifying Knowledge}


Griliches and Mairesse (1995) discuss the limited understanding we have about why firms are different in a set of essential variables, including the knowledge profile of the firms' employees, the technologies they apply, and the customer markets that they serve. Their conclusion is that research on these issues should be given high priority. Firms also differ with regard to knowledge assets and the ability to exploit such assets. In addition we recognize that firm knowledge has several dimensions as illustrated in Figure 2.

Throughout his contributions to the theory of technological change, Mansfield $(1968,1987)$ was careful to make a clear distinction between technology and techniques, stressing that technology has the status of knowledge about techniques. However, the concept of technology has evolved to allow formulations such as "technological knowledge". In Figure 2 we introduce another basic distinction which separates firm knowledge into (i) technical solutions and (ii) capabilities, where the latter associates with know-how and the former with specific designs of firm operations such as administrative and logistical routines, product attributes and production techniques in the narrow sense. There are two fundamental aspects of these two forms of knowledge: know-how and technical solutions are characterized by different development processes and by different probabilities of diffusing to other firms.

As will be elaborated further in this presentation, firm capabilities include experiences, skills and organization routines for development and accession of knowledge about technical solutions and for associated renewal activities aiming at innovation and adoption of new technical solutions. This view implies that capabilities partly develop as a side effect of renewal activities, including phenomena like learning by doing (Nelson and Winter, 1982; Cohen and Levinthal, 1990; Phene and Almeida, 2008). The outcome of the renewal activities is expanded capabilities and enlargement of the firm's library of technical solutions.

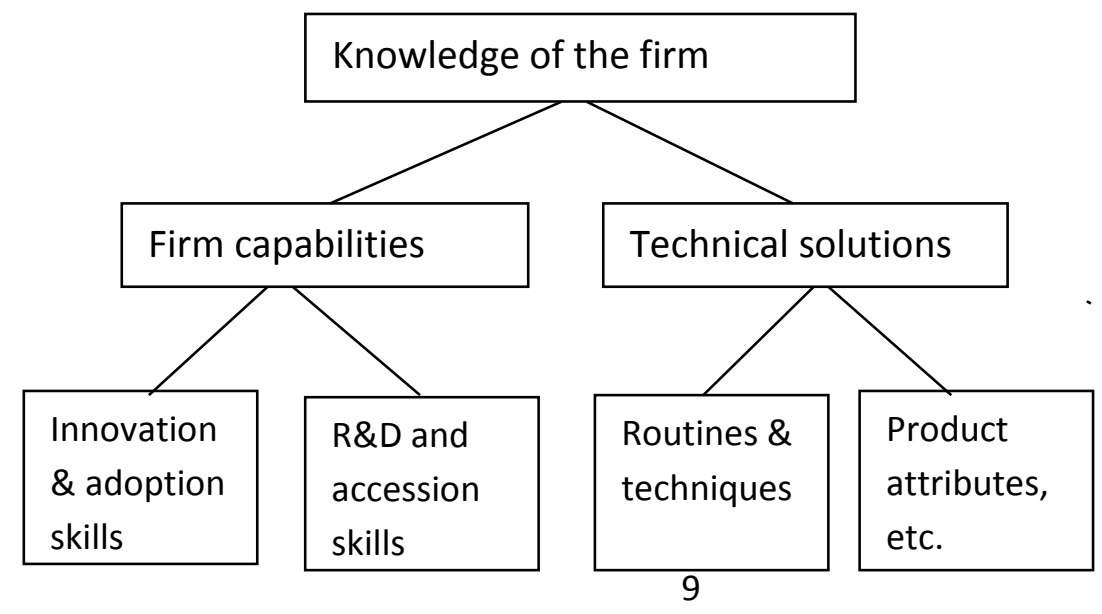


Figure 2: The two basic types of firm knowledge

Firm knowledge in the form of capabilities determines the firm's capacity and likelihood to succeed in its efforts to expand and sharpen knowledge about technical solutions. We suggest that capability knowledge shares many properties with other types of know-how. In particular, there are limited possibilities to codify capability knowledge and as a consequence it is difficult to transfer. The skills and abilities associated with capability knowledge also require maintenance which may be an integral part of a firm's intention to repetitively continue its research and renewal activities. A firm with such intentions will behave as if it followed a capability strategy, aiming at a continuous effort to maintain and develop its various renewal skills.

We suggest that the possibilities to codify capability knowledge are limited in concordance with assumptions in the literature about difficulties to codify all forms of know-how, arguing that capabilities are complex (Beckmann, 2000) and tacit in nature and therefore have to be transferred between persons (Polyani, 1966) in interactive learning processes. This also includes recruitment of new employees who embody renewal experiences, as well as new startups by persons with experiences from their previous employment in innovative firms.

The second type of knowledge in Figure 2 comprises technical solutions in a broad sense, subdivided into routines and product attributes, where routines refer to a firm's production processes, administrative and logistical processes. The second category of technical solutions relate to knowledge about product design (composition of attributes) and customer preferences with regard to attributes, including adjustments of deliveries. The firm may develop and access such knowledge, which still has to be transformed to innovation and/or adoption as an additional creative step

Following suggestions by Teece (2010), Dosi and Nelson (2010), Almeida and Phene (2012) and Cantwell and Zhang (2012), we conclude that remaining differences between the performance of firms should be associated with remaining differences in firm capabilities. Such differences will allow groups of firms to maintain productivity advantages as well as a more frequent introduction of new product varieties. It then remains to create indicators that can empirically reveal capability advantages. 


\section{INTERNAL KNOWLEDGE}

In the preceding section the presentation finds two basic notions of knowledge. The first one refers to a firm's knowledge about technical solutions and its implemented technology level. The second notion, capability, intends to reflect dynamics by considering a firm's know how with regard to creation and accession of new knowledge that can be transformed to innovation and adoption.

\subsection{Applying and Creating Knowledge}

In this subsection, which focuses on firms' internal knowledge, we collect modeling perspectives that distinguish between (i) knowledge creation and accession activities, (ii) innovation and adoption of new technical solutions, and (iii) effects of novelties on firm performance. We also refer to contributions that consider accumulation of firms' internal knowledge and make firm capabilities a key concept.

\section{Creation and Accumulation of Knowledge}

In recent decades we can observe how the theory of the firm has developed to focus on the firm's management of knowledge. For a long while firm-level analysis had been concerned with extending the firm's production function to include technology (knowledge about techniques) as a shift factor augmenting the firm's output per input factors, implying productivity growth. In such a setting the firm output, $Y$, is modeled as a function of capital, $K$, ordinary labour, $L$, knowledge workers, $H$, and a technology shift factor, $A$.

In this kind of formulation (Johansson and Lööf, 2008) the $H$-variable reflects the firm's internal capacity to develop its performance, which may be measured by the productivity of ordinary labour, calculated as $Y / L$, by productivity growth, $\Delta Y / L$ or by total factor productivity growth. In turn, the $A$-variable would reflect the performance effect of implementing new technical solutions such as improved product attributes and routines, where new routines save costs and improved attributes can augmet output prices an sales value. The empirical literature reveals that the knowledge intensity, $H /(H+L)$, correlates with firm performance as reflected by the productivity level. 
It is obvious that the formulation we have presented contains a structural confusion in the sense that the internal knowledge, as given by $H$, is an indicator of knowledge input (innovation input), whereas the $A$-component rather refers to consequences of innovation or adoption. We may illustrate this phenomenon by adding an equation for the $A$-factor, showing how the $A$-level increases as an effect of past renewal efforts with the help of knowledge workers, $H$, who participate in R\&D work, knowledge accession activities and efforts to adopt existing technical solutions.

In this widened formulation there are two parallel processes: One cumulates knowledge and the second applies the knowledge by implementing it as technology that improves output performance. The described renewal efforts may take place over time, to become useful at subsequent points in time. We may refer to endogenous growth theory and consider the concept R\&D capital, which represents accumulated R\&D or renewal efforts over a sequence of years (Hall, 2011). With this approach the R\&D capital corresponds to the technology shift factor. Obviously, introducing accumulation of knowledge capital also brings new questions about depreciation of the same capital. Such depreciation, reflecting creative destruction, would primarily affect the firm's "library of technical solutions", whereas renewal capabilities represent a more durable type of knowledge in the sense that it is difficult to copy.

\section{The CDM-Model Distinctions}

Sub section 3.1 presents a structured picture of how innovation and adoption are generated. Observing this phenomenon, Crépon, Duguet and Mairesse (1998) suggested a structural model, labeled the CDM-model, which is composed of three steps where the first step is knowledge creation ( $R \& D$ efforts), the second is innovation outcome, and the third step is productivity consequences of the innovation. In our discussion we stress the similarities rather than the differences between adoption and innovation, and then the three steps can be labeled as follows:

(i) $\quad \mathrm{R} \& \mathrm{D}$ and other renewal efforts

(ii) Innovation and adoption of novelties

(iii) Firm performance

The basic distinction in the CDM model is between creation and accession of new knowledge, and the use of this knowledge in improving the firm's performance in terms of productivity, productivity growth or export indicators such as new export varieties, export prices and 
quantities, etc. In Mairesse and Robin (2012) the three steps presented above are extended to four steps explaining in sequence (i) the probability that a firm engages in continuous or recurrent $R \& D$ efforts, (ii) a firm's $R \& D$ intensity, contingent on making recurrent $R \& D$, (iii) a firm's innovation output, and a firm's labor productivity.

An important finding in the Mairesse-Robin study is that the relevant innovation variable is overall innovation, incorporating process and/or product renewal. Table 1 presents factors that are shown to positively influence the probability of recurrent $R \& D$ and the $R \& D$ intensity. As can be seen, three significant factors are the same in both equations. However, among firms doing $R \& D$ the intensity is increasing for firms that make use of external knowledge sources (cooperation).

Table 1: Explaining the R\&D engagements of firms

\begin{tabular}{|l|l|}
\hline \hline $\begin{array}{l}\text { Probability of recurrent R\&D efforts is } \\
\text { explained by }\end{array}$ & $\begin{array}{l}\text { R\&D intensity, contingent on making R\&D } \\
\text { efforts is explained by }\end{array}$ \\
- International sales are larger than & - International sales are larger than \\
- domestic & - Appropriability protection \\
- Firm size & - Firm size \\
& - Cooperation with external actors
\end{tabular}

Source: Mairesse and Robin (2012)

The CDM-approach as applied in Table 1 detects a significant influence from knowledge created in cooperation with external actors. What about internal knowledge? In the subsequent analysis we will emphasize that the variable that indicates recurrent $R \& D$ efforts also expresses the presence of internal knowledge in the form of renewal capabilities that are generated as a learning effect.

\subsection{Developing Firm Capabilities}

In what ways can we claim that firms follow strategies for coping with an uncertain future? Can such a strategy be thought of as a conscious planning approach of a firm or is it a reconstruction of each firm's past behavior? Without resolving these questions we suggest that firms' innovation behavior can be described and analyzed by means of the concept 
innovation strategy, describing pro-active decisions about building up a firm's resource base (Barney, 1991; Teece, 2010). The resource base comprises the firm's renewal capabilities and its ability to apply these skills and competences in the process of developing technical solutions. In view of this, we may suggest the label capability strategy.

Figure 3 outlines the basic interdependencies between capability objectives of a firm and its efforts to find applicable technical solutions. A fundamental feature in this process is that the capabilities have to be maintained and improved through repetitive efforts to develop new technical solutions. In particular, the figure stresses that renewal efforts have a two-pronged outcome, as they bring about technical solutions and at the same time maintain and refine the renewal capability.

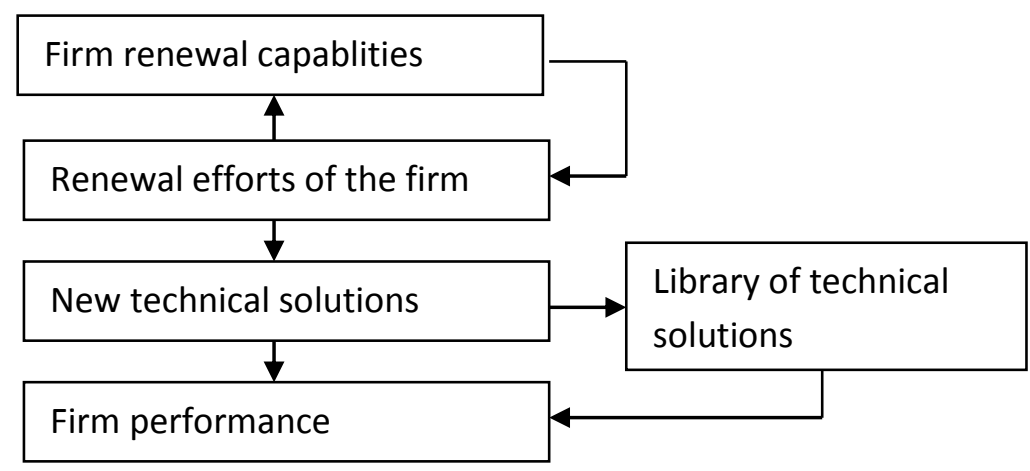

Figure 3: Renewal efforts generating new solutions and adding to firm capabilities

A central suggestion in our presentation is that renewal capabilities are the core of a firm's internal knowledge. This part of firms' internal knowledge can have long-term consequences in separating the performance level of different firms. We will elaborate on this phenomenon with two basic performance variables: the export of firms and the productivity of firms. While we do this, firm capabilities are indirectly observed as persistent sequences of (i) new product varieties, (ii) patent applications, and (iii) R\&D efforts - all proxies for persistent renewal efforts. The "size" of the internal capability-knowledge is indicated by the degree of persistent recurrence of the phenomena (i)-(iii) and similar indicators. 


\section{Capabilities Revealed by Arrival Rate of New Product Ideas}

Our major case recognizes a firm's number of export varieties as the result of its past innovation or adoption activities. This approach to identify capabilities of a firm is elaborated in a study by Andersson and Johansson (2012), who present a model with monopolistic compwetition, where each exported product variety is a unique combination of an export code, an export destination and a firm. Ideas that can lead to new varieties are generated by a Poisson process which is unique for each firm, such that the arrival rate for firm $i$, denoted by $\lambda_{i}$, measures the frequency of novel varieties per time period. Observing and estimating $\lambda_{i}$ for each firm $i$ provide us with a measurement of firm $i$ 's product renewal capability.

In a temporal setting it is possible to study the number of varieties of each firm over a sequence of years. For each year a firm's stock of varieties is a measure of its past innovative behavior, and this is assumed to influence the firm's current capability. A firm's number of varieties change between years according to a variety-entry and a variety-exit process. Given this, we have two results that shed light on the idea that the size of each firm's stock of varieties informs us about its capabilities. The first observation is based on arranging firms into groups, $j$, where $j$ indicates the number of varieties for firms in that group. In Table 2 for example, $j=1$ indicates 0 varieties and $j=4$ indicates 3-4 varieties.

Table 2: State transitions between years, 1998-2004

\begin{tabular}{|l|r|r|}
\hline \hline State in period $t$ & \multicolumn{1}{|c|}{$q_{i i}$} & $q_{i i}+q_{i, i-1}+q_{i, i+1}$ \\
\hline No export variety & $81.8 \%$ & $97.2 \%$ \\
\hline 1 variety & $31.6 \%$ & $81.8 \%$ \\
\hline 2 varieties & $23.2 \%$ & $71.6 \%$ \\
\hline 3-4 varieties & $32.3 \%$ & $74.9 \%$ \\
\hline $5-8$ varieties & $44.7 \%$ & $82.5 \%$ \\
\hline 9-12 varieties & $35.8 \%$ & $81.9 \%$ \\
\hline 13-16 varieties & $33.1 \%$ & $89.9 \%$ \\
\hline More than 16 varieties & $92.9 \%$ & $97.2 \%$ \\
\hline \hline
\end{tabular}

Source: Andersson and Johansson (2012)

Having classified firms into size groups (in terms of the number of export varieties), we can for each pair of years calculate transition probabilities, $q_{i j}$, showing the share of firms that shift from class $i$ to class $j$ between two subsequent years. The probability $q_{i i}$ shows the likelihood to remain in class $i$ for two years in sequence. From the table we can see that the 
probability of remaining a non-exporter is greater than 80 per cent, while the probability of staying in the group 5-8 varieties is 44.7 per cent.

Table 2 illustrates that firms increase and decrease their number of varieties. However, the table also reflects that the stock of varieties changes slowly from year to year, and a large fraction of the firms changes at most one interval up or down in the hierarchy, which is recorded by the probability $q_{i i}+q_{i, i-1}+q_{i, i+1}$. For example, more than 97 per cent of the firms in the group with more than 16 varieties continues to export more than 16 varieties or drop to the group with13-16 varieties. Thus, there is a clear feature of inertia in the innovation/adoption variable, and each firm's capability level develops on a slow time scale: firms with no export variety rarely introduce any variety, whereas firms with many varieties continue to have many varieties by persistently introducing new ones as old ones exit.

Consider now that firms with a small number of export varieties also can be expected to have a low arrival rate with regard innovation/adoption ideas (variety ideas), whereas firms with large stocks of varieties have a high arrival rate. For the latter this is reflected by a high $\lambda_{i}$ value, indicating a large capability. Thus, when $\lambda_{i}$ is large a new variety idea is a frequent event and the variety-renewal activities are persistent. When $\lambda_{i}$ is small the renewal capability is small and novelties are rare. This leads to the question: what factors influence the renewal capacity? In a regression analysis by Andersson and Johansson (2012) the following set of factors are shown to influence positively firm $i$ 's value of the new-variety arrival parameter $\lambda_{i}$ :

- The firm's variety stock

- The firm is an exporter (dummy)

- The firm is an importer (dummy)

- The firm size measured by employment

- The firm's share of knowledge-intensive labor

- Export intensity of the firm

- Labor productivity of the firm

- The firm belongs to a multinational company group

- Number of persistent exporters in the region hosting the firm 
The described regression result is based on entry of varieties between 1998 and 2004 with Swedish data. The regression is conditioned on initial values (explanatory variables observed for the initial year 1998). We should emphasize that the econometric result is obtained from a model, where the historically given variety stock at date $t$ affects the arrival rate (renewal capability) during a subsequent period up to $t+\tau$. This may be interpreted as path dependence. At the same time we conclude from the regression results that firm capabilities also rely on established export and import networks as well as knowledge networks inside a multinational company group. All these factors are also represented in the list of explanatory variables above.

The logic of the findings runs as follows. A high capability in the past (high arrival rate) results in a large variety stock, which stimulates a continued high introduction of new varieties. This is supported by a large share of knowledge-intensive labor in the firm, by potential global knowledge-flows for firms belonging to a multinational company group, by knowledge spillovers related to the firm's export and import activities, and a regional milieu of persistent exporters.

\section{EXTERNAL KNOWLEDGE SOURCES}

The concept knowledge accession strategy is introduced in Cantwell and Zhang (2012), where we are told that the generation of new knowledge has the form of a process which combines and recombines current and acquired knowledge. The external knowledge can be accessed in a firm's local milieu or in a global environment. Section 4 examines the importance of the local milieu.

\subsection{Potentials for Knowledge Interaction}

A firm can access external knowledge in different ways. The knowledge may be purchased or transferred according to a license contract, it can move into the firm through new employees who bring with them know-how and knowledge about technical solutions from places where they have worked earlier in their career, and it can spill over from collaborative efforts with other firms and research organizations like universities.

Krugman (1991) suggests that spillovers cannot easily be measured and tracked because knowledge flows are invisible to a large extent. However, more recent research has made important progress in the attempt to open the black box. For instance, a range of empirical 
studies show that the social rate of return differs across locations and that knowledge flows diminish in volume and intensity as the distance between origin and destination grows.

In case studies one may find out actual channels for knowledge flows and ask question about the importance of proximity when citing patents, when establishing cooperation links with other actors, and when searching for new employees who embody attractive knowledge. An alternative way is to introduce a potential measure that defines a field of influence which affects knowledge flows in a relevant geography. Jaffe et. al. (1993), and Feldman and Audretsch (1999) examine how aggregate knowledge sources and R\&D activities inside an urban region generate spillovers and affect innovation activities and outcome of firms located in the region. Different studies of this type conclude that knowledge flows and spillovers are spatially bounded.

As an alternative to the approach above, we consider a finer spatial resolution for which information is available about location of firms and location of knowledge sources. In such a setting the following model formulation can be applied. The model identifies locations $i$ and $j$, and the time distance, $t_{i j}$, between each such pair of locations. The next step is to collect information about the size of a selected type of knowledge source, $G_{j}$, in location $j$. For any firm in location $i$ we define the firm's distance-discounted knowledge potential with regard to $G_{j}$ as

$$
M_{i j}=\exp \left\{-\lambda t_{i j}\right\} G_{j}
$$

where $\lambda$ is an estimated parameter expressing time sensitivity for making face-to-face contacts between two localtions, observing that contacts inside a location also have a time distance, signified by $t_{i i}$. Using formula (4.1) we can calculate the entire external knowledge potential that firms in location $i$ have as $M_{i}=\sum_{j} \exp \left\{-\lambda t_{i j}\right\} G_{j}$. Moreover, the knowledge of the very local milieu is given by $M_{i i}=\exp \left\{-\lambda t_{i i}\right\} G_{i}$. We may remark that the knowledge-potential measures ( $M$-values) can be given a probability interpretation so that (4.1) provides a measure of expected knowledge contacts between actors in location $i$ and knowledge sources in location $j$, based on random-choice behavior or accessibility ccalculations (Johansson and Klaesson, 2011; Weibull, 1976). 
Now it remains to discuss which knowledge resources that may be reflected by the $G$ variable. We shall do that briefly by listing alternatives that span a small universe of candidates. A general observation is that the value of (4.1) with different definitions of $\mathrm{G}$ will often be highly correlated. The $G$-value in a given location can be a measure of either of the following values in the selected location:

(i) The size of university R\&D (spending or man-years)

(ii) The size of R\&D efforts made by private industry

(iii) The number of knowledge-intesive workers in the entire economy of the location

(iv) The number of patent applications and/or patents granted

(v) The supply of knowledge-intensive producer services (employment or economic value of the supply)

Other candidates can be a measurement of export experiences or import experiences, recording the number of exporters and importers. The two alternatives (i)-(ii) are employed in a study by Andersson and Gråsjö (2009) where the time-discounted values manage to capture most of the spatial interdependencies. The authors find that industry R\&D is a more powerful knowledge source than university $R \& D$, although locations with much industry R\&D tend to host university R\&D too. Alternative (iii) which captures the overall knowledge-intensity in locations is applied by Andersson and Johansson (2010), who name their $G$-value external human capital, sub divided into human capital in neighboring locations and human capital in other industries.

Alternative (v) has recently been applied in Johansson, Johansson and Wallin (2014) in a study that compares the influence on export-product renewal from the internal and external knowledge sources accessible to local industries, in a paper by Lööf, et.al. (2014) that examine the role of the local knowledge milieu in determining firms' propensity to be persistent exporters and their TFP growth rate, and in Lööf, Nabavi and Johansson (2012) illuminating how firms can benefit from access to knowledge-intensive producer services. In the following sub section these recent contributions are examined with the intention to clarify the coupling between local knowledge milieu and firm performance indicators.

The strength of the distance decay of the market potential has important implications for analyzing knowledge flows, diffusion and spillover phenomena, and it should be seriously 
investigated to find out if different types of knowledge flows have the same time-distance sensitivity or not. A related issue is the precise delineation of local and regional knowledge potentials, respectively.

\subsection{Local Milieu and Global Networks}

There is a growing amount of evidence that knowledge sources in the local and regional environment of firms generate knowledge transactions and spillovers that affect firm performance. We have noted that a knowledge potential may represent the possible renewal influences that a given firm may get. This idea may be further enriched by adding information about the technology relatedness in the local knowledge milieu. In this way it might become possible to extend our deliberations on spatial factor proportions in the context of renewal activities.

Another strand of analysis stresses that attempts to access external knowledge can be appreciated as a strategy-driven process, in which the firm actively searches for knowledge inputs to the firm's ambition of building up its internal knowledge. In this context the firm is assumed to find new information for knowledge building by establishing formal and informal links to other actors such as its input suppliers, its customers, universities and other knowledge providers. A firm can influence its knowledge-flow environment by establishing formal and informal links to other actors such as input suppliers, customers, universities and other knowledge providers. Network development of this kind is less costly to carry out inside an urban region, and the advantage of being in a region that offers a large knowledge potential lies in the fact that the number of potential contacts is larger and more diversified than elsewhere (Simmie, 2003).

Consider now that the size of an urban region is a characteristic of the local milieu of firms in the urban region. We observe that large urban regions have large labour markets with a rich variety of specialist competence structures and more inter-firm job mobility. Having said this, we also recognize that labour mobility is a process which allows knowledge to spill over from a firm's environment, affecting its knowledge formation. This form of embodied knowledge flows can in addition be part of a firm's recruitment strategy (Andersson and Thulin, 2011).

Besides knowledge flows from the local milieu, the literature also considers knowledge flows that materialize in long-distance links of international networks. The firm may have established links for imports from input suppliers abroad as well as links for export to 
customers abroad. Moreover, firm's may build trans-national links for R\&D collaboration with firms abroad. In Swedish data a major indicator of the presence of international knowledge flows seems to be that a firm is part of a multinational company group (Lööf and Nabavi, 2014).

\subsection{The Conjunction Hypothesis}

When introducing the present chapter we have refered to challenging contributions by Almeida and Phene (2012) and Cantwell and Zhang (2012). In both cases the focus is primarily on large corporations with links to knowledge sources both in the local mileus and international sources. The two contributions emphasize that knowledge management of such firms concerns the possibilities of combining internal and external knowledge components, and the capacity to access external knowledge and integrate it in the in-house renewal efforts. In this presentation we suggest that this conjunction idea is relevant for firms of different sizes and with different ownership structures.

The contribution that we claim to do is to introduce a conjunction variable that informs about how and in what proportions a firm's internal and external local knowledge are combined. One approach to formulate a conjunction variable is to make use of information about each firm's renewal strategy and its local knowledge potential, grouping firms into 9 categories as specified in Table 3. In this classification $\mathrm{C} 1$ represents an extreme category where firms make infrequent or no renewal efforts, whereas category C9 consists of firms that are persistently engaged in renewal efforts. Once the categories have been arranged, one may examine to what extent each category associates with firm performance.

Table 3: Construction of 9 conjunction-variable categories

\begin{tabular}{|l|l|l|l|}
\hline \hline Renewal strategy & $\begin{array}{l}\text { Low external } \\
\text { knowledge potential }\end{array}$ & $\begin{array}{l}\text { Medium-sized external } \\
\text { knowledge potential }\end{array}$ & $\begin{array}{l}\text { High external } \\
\text { knowledge potential }\end{array}$ \\
\hline No efforts & $\mathrm{C} 1$ & $\mathrm{C} 2$ & $\mathrm{C} 3$ \\
\hline Occasional engagement & $\mathrm{C} 4$ & $\mathrm{C} 5$ & $\mathrm{C} 6$ \\
\hline Persistent engagement & $\mathrm{C} 7$ & $\mathrm{C} 8$ & $\mathrm{C} 9$ \\
\hline
\end{tabular}

The approach illustrated in Table 3 is related to the assumption that a firm's renewal strategy can be used to indicate the size of the firm's internal knowledge. The argument is that 
persistent renewal efforts in the past reflect formation and maintenance of renewal capabilities of the firm. In the examples presented in Section 5, we apply alternative indicators to determine which renewal strategy a firm follows. One such indicator is based on measuring how often a firm makes patent applications. Another indicator is a firm's statement in the CIS surveys about its engagement in R\&D efforts in the past.

A second way to form a conjunction variable is represented by the following specification, $C_{i j}$ for a firm $i$ (or a local industry $i$ ) in local economy $j$ :

$$
C_{i j}=\Lambda_{i} \ln M_{j}
$$

where $\Lambda_{i}$ equals one if $i$ has internal knowledge above average and zero otherwise, and where $M_{j}$ provides a measure of the external knowledge potential associated with location $j$. In the example presented in the next section, the internal knowledge is calculated as the sum of university-education years among the employees of $i$. A similar measure is the number of knowledge-intensive employees (with at least three years of university studies).

A third option to form a conjunction indicator makes use of a distinction between firms located in a metropolitan region with reference to non-metropolitan locations, and firms located in a metropolitan city with reference to non-metropolitan locations, where a metropolitan city is the largest city in a metropolitan region. The classification that obtains in this case refers to the assumption that the local knowledge-potential is greater for a metropolitan location than for other locations.

As an additional external knowledge indicator we may also consider if a firm is a member of a company group or not. The distinctions in this case are non-affiliated firms, firms that belong to a uninational, a domestic multinational group and a foreign multinational group. This classification corresponds to the suggestion that members in a multinational group can make use of internal interaction links to transmit knowledge from global knowledge sources. Such an advantage requires that the individual members of a group are fit for absorbing knowledge flows in their respective local milieu.

The conjunction hypothesis can be applied to investigate a series of questions, such as:

(i) Can a firm with limited internal knowledge compensate for this by being located in a place with a large knowledge potential? 
(ii) To what extent can a firm carry out its renewal activities, relying solely on its internal knowledge?

(iii) Does the amount of internal knowledge determine how successful the firm is in its knowledge accession activities?

(iv) Are internal and external knowledge substitutes or complements in a firm's renewal activities?

\section{EMIRICAL EVIDENCE IN FAVOUR OF THE CONJUNCTION HYPOTHESIS}

Section 5 provides three examples of attempts to capture the effects on firm performance that results from a firm's capability of combining internal and external knowledge. The three examples vary the way performance is measured, the way internal knowledge is identifies and the way external knowledge is reflected.

\subsection{Productivity Effects of Combined Internal and External Knowledge}

In this sub section we provide a detailed example of an attempt to illuminate how the combination of a firm's internal and external knowledge affect firm performance. The presentation makes use of findings in Lööf, Nabavi and Johansson (2012). As a measure of each firm's external knowledge the study relies on information about the firm's knowledge potential as introduced in sub section 4.1. Given this, the empirical analysis applies two alternative measures of each firm's internal knowledge, where the first measure is based on reports from firms in three consecutive CIS waves covering the period 2000-2008 -with 40 per cent of the firms observed in all three surveys and 60 per cent in two surveys. The second measure is based on firms' patent applications during the period 1997-2008.

Based on information about firms' patenting behavior and on information from the CIS surveys, firms are assumed to have a large internal knowledge base when they have a long history of persistent renwal efforts, to have medium-sized internal knowledge when they have a history of occasional renewal efforts, and to have a small internal knowledge when they have a history of no renewal efforts. The criteria applied are reported in Table 4. 
Table 4: Classification of firms with regard to size of internal knowledge

\begin{tabular}{|l|l|l|}
\hline \hline $\begin{array}{l}\text { Size of internal } \\
\text { knowledge }\end{array}$ & CIS-based renewal efforts & $\begin{array}{l}\text { Number of years with patent } \\
\text { applications }\end{array}$ \\
\hline Large & All years that are observed & At least 6 out of twelve years \\
\hline Medium & Less than all years & $1-5$ out of twelve years \\
\hline Small & No years & 0 out of twelve years \\
\hline
\end{tabular}

It is quite clear that the two types of indicators in Table 4 are not conveying identical information about a firm's internal knowledge. In spite of this, they still sort firms in three groups where each pair of groups has similar impacts on firm performance. In the study referred to here, performance is also recorded in two alternative ways. The first performance variable is labor productivity of each individual firm, which is a measure in level, whereas the second variable records firms' TFP growth.

\section{Knowledge Conjunction Effects on Value Added}

According to Table 3 the conjunction variable, C, associates each firm with one of the indicators C1-C9. A basic question is how these indicators affect three firm's output, measured by value added in a regression with a panel using capital, labor, ownership, knowledge iintensity, lagged value added and time dummies as regressors, applying the Blundell and Bond (1998) twp-step system GMM estimator allowing for a distinction between endogenous, pre-determined and exogenous roght-hand side variables. This is presented in Lööf, Nabavi and Johansson (2012) with two alternative ways of classifying firms into persistent, occasional and inactive innovators.

For each firm $i$ the conjuction variable shows the conjunction impact via a regression parameter $\beta(i)=\beta_{K}$ as $i$ belongs to $K=\{C 1, C 2, \ldots, C 9\}$, and we can write $\beta_{K}=\beta(C k)$, with $k=1, \ldots, 9$. The category parameter is ordered according to size of impact for two alternative regressions. In the first column internal knowledge is reflected by patent application frequency, and in the second CIS data are used as indicator of internal knowledge. 
Table 5: Impact of the conjunction variable on a firm's output (value added)

\begin{tabular}{|l|l|}
\hline $\begin{array}{l}\text { Order of impact size as patent } \\
\text { applications are used as indicator of } \\
\text { internal knowledge }\end{array}$ & $\begin{array}{l}\text { Order of impact size as CIS } \\
\text { information is used as indicator of } \\
\text { internal knowledge }\end{array}$ \\
\hline$\beta(C 9)>\beta(C 8)>\beta(C 7)>$ & $\beta(C 9)>\beta(C 8)>\beta(C 7)>$ \\
\hline$\beta(C 6)>\beta(C 5)>\beta(C 4)>$ & $\beta(C 6)>\beta(C 5)>\beta(C 3)$ \\
\hline$\beta(C 3)>\beta(C 2)>\beta(C 1)=0$ & $\beta(C 4)$ and $\beta(C 2)$ are insignificant \\
\hline & $\beta(C 1)=0$ \\
\hline
\end{tabular}

The result in the left column of Table 5 is salient in the sense that the $\beta$-parameter is influenced by both the internal and external knowledge of the firm and that value added is a strictly increasing function of the combination of internal knowledge generation and external knowledge proximity. Another observation is that $\beta(C 2)$ is smaller than 1 per cent, whereas $\beta(C 9)$ is larger than 20 percent. When internal knowledge instead is identified in the CIS panel (which corresponds to a broader concept of knowledge activity in the firm) a similar but less strict result obtains, where we observe that two of the $\beta$-parameters are not significantly different from zero.

The results reported in Table 5 appear in settings where the impact of belonging to a multinational company group is statistically significant and large, informing us that such company groups are likely to have considerable advantages in accessing global knowledge that is external to the individual firm.

\section{Knowledge Conjunction Effects on TFP Growth}

For the case where firm performance is recorded as TFP growth, the total factor productivity change is measured in two steps, following the approach of Levinsohn and Petrin (2003). In the first step TFP is computed as the residual of a Cobb-Douglas production function where a firm's value added is the dependent variable, and where the determinants are inputs of ordinary labor, university-educated labor, and physical capital. In the second step the growth of TFP is estimated with a technique that applies a dynamic panel modell with error component decomposition (Lööf, Nabavi and Johansson, 2012).

As shown in Table 6 the impact of the conjunction variable on TFP growth follows theoretical predicitions in the left-hand column (for the first six categories) when the internal knowledge 
is reflected by patent-application frequency. In the right-hand column we can see that the ordering of the $\beta$-parameters follow theory predictions only for the first three categories, indicating that CIS information on $\mathrm{R} \& \mathrm{D}$ persistence may not be fully adequate.

Table 6: Impact of the conjunction variable on a firm's TFP growth

\begin{tabular}{|l|l|}
\hline $\begin{array}{l}\text { Order of impact size as patent applications } \\
\text { are used as indicator of internal knowledge }\end{array}$ & $\begin{array}{l}\text { Order of impact size as CIS information } \\
\text { is used as indicator of internal knowledge }\end{array}$ \\
\hline$\beta(C 9)>\beta(C 8)>\beta(C 7)>$ & $\beta(C 9)>\beta(C 8)>\beta(C 7)>$ \\
\hline$\beta(C 6)>\beta(C 4)>\beta(C 5)$ & $\beta(C 6)$ is insignificant on the 5 \% level \\
\hline $\begin{array}{l}\beta(C 3) \text { and } \beta(C 2) \text { are small in value with a } \\
\text { low significance level }\end{array}$ & $\beta(C 5)-\beta(C 2)$ are insignificant \\
\hline$\beta(C 1)=0$ & $\beta(C 1)=0$ \\
\hline
\end{tabular}

The empirical results presented in sub section 5.1 sum up to the conclusion that firms have a superior performance when they manage to combine internal knowledge based on persistent innovation efforts with an environment offering a high knowedge potential. Even when the knowledge environment is poor, firms with high internal knowledge outperform occasional innovators in environments with a high knowledge potential.

\subsection{Export Varieties and Combined Internal and External Knowledge}

In this subsection we consider an alternative type of indicator to reflect firm performance, while also recognizing that a firm's renewal efforts can be based on adoption as well as innovation activities. The short story to be told is based on Johansson, Johansson and Wallin (2014). The focus is the export performance of local industries, where each local industry is identified as a 2-digit industry located in one out of 290 urban areas (municipalities). For each such local industry the study identifies its (i) internal knowledge reflected by the education of employees, (ii) its external knowledge in the form of supply of knowledge-intensive producer services, and (iii) a conjunction variable that reflects the combination of internal and external knowledge.

\section{Variables that Reflect Export Performance of Local Industries}

Export performance of a local industry is identified in five dimensions, comprising (i) total export value, number of exporting firms, (iii) average number of code-destination specific 
varieties per exporting firm, (iv) average unit price of code-destination specific varieties per firm, and (v) average export quantity of code-destination specific varieties per firm. A codedestination variety is an 8 digit product code and a destination country, which means that an export variety is a triplet, identified by a unique combination of firm, code and destination. Thus, the study examines how local industries have introduced export triplets reflected by total export value, $V$, number of exporting firms, $F$, number of code-destination varieties, $N$, price, $P$, and quantity, $\mathrm{Q}$, so that $V=F \times N \times P \times Q$, with the following specification:

$V_{j s}=$ Export value for industry $s$ in location $j$

$F_{j s}=$ Number of exporting firms for industry $s$ in location $j$

$N_{j s}=$ Average number of code-destination varieties per firm in local industry $(j, s)$

$P_{j s}=$ Average price of code-destination varieties in local industry $(j, s)$

$Q_{j s}=$ Average quantity of code-destination varieties in local industry $(j, s)$

Since $V=F \times N \times P \times Q$, the five variables above satisfy the condition $\ln V_{j s}=\ln F_{j s}+$ $\ln N_{j s}+\ln P_{j s}+\ln Q_{j s}$, and it is possible to determine how each variable contributes to the total export value. In the sequel the discussion concentrates on the four variables $V, F, N$ and $P$ as candidates for performance variables that are positively associated with internal and external knowledge as well as the interaction between internal and external knowledge (conjunction variable). Central questions are: does the conjunction variable have a positive effect on (i) the export price, (ii), the number of triplets, and (iii) the number of firms? Moreover, how is the total export value influenced by the conjunction variable?

\section{Knowledge and Knowledge Conjunction Effects on Export Performance}

Sections 3 and 4 provide a broad outline of how internal and external knowledge of firms and industries can stimulate firm renewal activities that in turn can have positive effects on firm performance, including export performance. The renewal activities bring about new export firms, new export variety triplets and may elevate the unit price of export flows, based on both adoption and innovation, which are both activities that require knowledge sources. In view of this, performance of a local industry is recorded by the number of export firms, the number of export varieties, the price of export varieties, and the total export value. In the study reported here (Johansson, Johansson and Wallin, 2014) these performance variables are regressed against knowledge sources 2002 and 2006. In addition the study also conducts the 
same type of regressions for export variety triplets that are introduced in the interval 20022006 (and hence new), conditioned on knowledge sources in 2002.

The log-linear regression employs industry dummies and the following regressors:

(i) The internal knowledge of a local industry, measured by the total number of university-education years among employees

(ii) The external knowledge, captured by the knowledge potential $M_{i}=\sum_{j} \exp \left\{-\lambda t_{i j}\right\} G_{j}$ in location $i$ as presented in sub section 4.1

(iii) The conjunction variable $C_{s j}=\Lambda_{s j} \ln M_{j}$ where $M_{j}$ is the knowledge potential of location $j$, and where $\Lambda_{s j}$ equals unity if the internal knowledge of local industry $(j, s)$ is above average and zero otherwise

(iv) The size of a local industry measured by the number of employees

Table 7 provides an overview of regression results for the four export-performance indicators. The first observation is that the number of exporting firms and the export value are positively associated with the three sources internal knowledge, external knowledge and knowledge conjunction. The number of variety triplets per firm is influenced by the conjunction variable and the internal knowledge. The results in the table also indicate internal and external knowledge has a positive price effect.

Table 7: Knowledge sources and export performance of local industries 2002 and 2006

\begin{tabular}{|l|c|c|c|c|}
\hline \hline Explanatory variables & $\begin{array}{l}(\boldsymbol{F}) \text { Number of } \\
\text { firms }\end{array}$ & $\begin{array}{l}(\boldsymbol{N}) \text { Variety } \\
\text { triplets per firm }\end{array}$ & $\begin{array}{l}(\boldsymbol{P}) \text { Average } \\
\text { variety price }\end{array}$ & $\begin{array}{l}(\boldsymbol{V}) \text { Export } \\
\text { value }\end{array}$ \\
\hline Internal knowledge & + & + & + & + \\
\hline External knowledge & + & - & + & + \\
\hline Knowledge conjunction & + & + & 0 & + \\
\hline Size of local industry & + & + & - & + \\
\hline
\end{tabular}

Remark: (+) denotes positive and significant, (0) denotes insifnificant, and (-) denotes negative and significant, where the significance level is one percent.

Table 7 suggests that the conjunction of internal and external knowledge sources adds to the knowledge milieu of local industries. A similar exercise for the introduction of new variety triplets generates similar results, although the conjunction variable deviates in this case - with positive influence on the number of export firms and average export quantity. It may be observed that the variables external knowledge and knowledge conjunction reflect both technology externalities and pecuniary externalities associated with the economic milieu of 
the localized exporting industries (Antonelli, 2013). Moreover, the knowledge-potential variable attempts to capture accumulated knowledge in local economies and its influence on the export performance indicators.

\subsection{Productivity and Metropolitan Milieus}

In this sub section we provide a third empirical example of how a firm's innovation strategy and its external knowledge potential combine to a composite variable that explains firm performance, which in this case is a labor productivity measure. The example is based on Lööf and Johansson (2012) in a setting where metropolitan location is assumed to offer a knowledge milieu that bring innovation advantages that are superior to the milieu afforded in other locations. This form of advantage is cross-classified with each firm's innovation strategy that is characterized by one of the following three alternatives: (i) no R\&D, (ii) occasional R\&D, and (iii) persistent R\&D efforts.

\section{Knowledge Milieu of Metropolitan Locations}

The approach presented here is special in two ways. First, we assume (as argued in previous sections) that a firm's innovation strategy can be used as a reflection of its internal knowledge. Second, it assumes that the knowledge sources are richer in a metropolitan location than in other locations. The set of non-metro locations is kept constant while varying a metro location to be (i) Sweden's three metropolitan regions, (ii) the largest region of these three, (iii) the three metropolitan cities that are centers of the three metropolitan regions, and (iv) the largest metropolitan city. In the sequel we summarize the literature that suggests that metropolitan milieus provide richer and more diversified knowledge-flow opportunities than other locations

A firm can influence its knowledge-flow environment by establishing formal and informal links to other actors such as its input suppliers, its customers, universities and other knowledge providers. Network development of this kind is less costly to carry out inside an urban region, and the advantage of a metropolitan region lies in the fact that the number of potential contacts is much larger and more diversified than elsewhere (Simmie, 2003). Large urban regions have also large labor markets with a rich variety of specialist competence structures and a more intense inter-firm job mobility, particularly among knowledge intensive wokers (Cohen and Levintal, 1990: Almeida and Kogut, 1999; Andersson and Thulin, 2008). 
Moretti (2004) suggests that plant productivity is an increasing function of external human capital in the local milieu, while Lychagin et al. (2010) finds that geographical markets are very local, which is in line with Lamorgese and Ottaviano (2006) and others who recognize that spillovers rapidly fade away with distance. Crespi et al. (2008) report that nearby suppliers and competitors (though less so customers) are primary sources of external knowledge. They also find that much of this information, particularly from competitors, is free, but not given freely, and that the presence of multinational firms makes these flows more intense. Goolsbee and Klenow 2002 report that larger regions and cities may have greater availability of complementary services which reduce the costs of adopting and implementing complex technologies.

\section{Productivity Premium for Six Combinations of Internal and External Knowledge}

The paper by Lööf and Johansson (2012) examines the importance of the local and regional environment for firms that employ one of the following three categories of innovation strategy: (S1) no R\&D efforts, (S2) occasional R\&D efforts, and (S3) persistent R\&D efforts. For each of these three categories, we assess the importance of firm location, classified into the following five types: the entire group of metropolitan regions, the largest metropolitan region, the group of metropolitan cities, where such a city is the urban center of a metropolitan region, the largest metropolitan city, and the entire group of non-metropolitan locations? To reveal how different combinations of strategy and location affect firm performance, we use the Community Innovation Survey (CIS) on Swedish manufacturing and service firms observed 2002-2004, and combine that information with register data for the observed CIS firms over the period 1997-2006. Due to the lag structure of the applied dynamic GMM model (Blundell and Bond 1998), the panel estimates refer to firm characteristics over the period 2000-2006. The majority of firms, almost 60 percent, have no R\&D-activities.

Table 8 cross-classifies firms with regard to innovation strategy and type of location, which yields six different categories of firms. The strategy labeled S3 represents the largest amount of internal knowledge and S1 the smallest. In the regression analysis the set of non-metro firms is invariant, whereas metro location is varied so that four distinct regressions obtain. 
Table 8: Definition of six category variables

\begin{tabular}{|l|c|c|c|}
\hline \hline & S1 = No R\&D & S2 = Occasional R\&D & S3 = Persistent R\&D \\
\hline Non-Metro & MR1 & MR3 & MR5 \\
\hline Metro & MR2 & MR4 & MR6 \\
\hline \hline
\end{tabular}

The empirical analysis consists of four regression equations, where each is based on a production function specified as follows for each point in time:

$$
Y_{i}=A_{i} F\left(H_{i}, K_{i}, L_{i}\right)
$$

where $Y_{i}$ denotes output of firm $\mathrm{I}$ in terms of value added, $H_{i}$ denotes the number of employees with at least three years of university education, $K_{i}$ denotes the input of physical capital, and $L_{i}$ the input of ordinary labor. The variable $A_{i}$ is a shift factor that indicates which of the six categories MR1,.., MR6 that firm $i$ belongs to. The labor productivity is calculated as $y_{i}=Y_{i} / L_{i}$. Adding a dynamic specification and identifying ownership and sector, while allowing for a lag structure of the regressors, the exercise yields that results presented in Table 9.

Table 9: Productivity premium in per cent associated with the six category variables

\begin{tabular}{|l|c|c|c|c|}
\hline \hline & $\begin{array}{l}\text { Group of 3 Metro } \\
\text { regions }\end{array}$ & $\begin{array}{l}\text { Largest Metro } \\
\text { region }\end{array}$ & $\begin{array}{l}\text { Group of 3 Metro } \\
\text { cities }\end{array}$ & Largest Metro city \\
\hline MR1 & Referens & Referens & Referens & Referens \\
\hline MR2 & Insignificant & Insignificant & Insignificant & Insignificant \\
\hline MR3 & Insignificant & Insignificant & Insignificant & Insignificant \\
\hline MR4 & Insignificant & Insignificant & Insignificant & Insignificant \\
\hline MR5 & 7.6 & 6.9 & 7.4 & 6.2 \\
\hline MR6 & 9.7 & 9.8 & 12.5 & 13.3 \\
\hline \hline
\end{tabular}

The results in Table 9 can be summarized in the following three statements. First, we observe that the productivity premium that follows from persistent R\&D efforts is around 8 per cent in non-metropolitan locations and about 14 percent in the largest metropolitan city. Second, no productivity premium is associated with occasional R\&D efforts, regardless of the firm's location. Third, firms with no R\&D engagements do not benefit from the external milieu in metropolitan areas. In summary, Table 9 signals that metropolitan cities in Sweden provide a superior milieu of knowledge sources and, as emphasized in Antonelli (2013), lower accession costs of external knowledge. 
To put the result in Table 9 in perspective, we may ask: how invariant is the classification of firms into six categories. An answer is provided in Table 10, which reports for each category the proportion of firms that did not belong to the category two years in sequence, signified by $\mathrm{o} / \mathrm{o}$, and the proportion of firms that did belong to the same category two years in sequence, signified by $1 / 1$. A high degree of invariance is observed for the entire period 1997-2006. The persistency covers the type of location and the type of innovation strategy.

Table 10: Year-to-year persistence in the same classification.

\begin{tabular}{llcc}
\hline \hline Variable & Definition & $0 / 0$ & $1 / 1$ \\
\hline$M R 1_{\text {it }}$ & Non - Metro $\times$ Non-R\&D & 99.65 & 99.40 \\
$M R 2_{\text {it }}$ & Metro $\times$ Non-R\&D & 99.68 & 99.53 \\
$M R 3_{\text {it }}$ & Non-Metro $\times$ Occasional R\&D & 99.90 & 99.40 \\
$M R 4_{\text {it }}$ & Metro $\times$ Occasional R\&D & 99.91 & 97.22 \\
$M R 5$ & Non-Metro $\times$ Persistent R\&D & 99.82 & 99.17 \\
MR6 & Metro $\times$ Persistent R\&D & 99.84 & 97.12 \\
\hline \hline
\end{tabular}

Notes

0/0: The proportion of firms that did not belong to this group in one year that also did not belong to this group the next year.

1/1: The proportion of firms that belonged to this group in one year that also belonged to this group the next year.

\section{CONCLUDING REMARKS}

The story told in this chapter has several motivations, ranging from consistency requirement and empirical regularities. First, observations on firms over time reveal that they are heterogenous both with regard to inputs and outputs. Second, the firm heterogeneity displays time invariance with lasting performance differences, with little evidence in favour of convergence to best practice conditions in each industry. Is there a theoretical framework that can host these observations? The presentation in this chapter represents a first attempt to sketch such a framework.

The outline in this chapter associates firm performance differences with the type of innovation strategy applied by each firm, ordered into S1 signifying negligible innovation efforts, S2 signifying occasional efforts, and S3 indicating persistent efforts. The presentation assembles evidence that implies that with the S3-strategy a firm can generate new technical solutions, while at the same time cumulating in-house knowledge that determines the firm's capability of continuing to remain innovative, a capability that is difficult to imitate. In this way persisting differences between innovation strategies can shed light on time-ivariant firmperformance differentials. 
Given the above conclusions, innovation and capability strategies are used as indicators of how large a firm's internal knowledge is. Then the chapter adds the question: how much do a firm's opportunities to access external knowledge influence its innovation capability? Is the usefulness of a generous knowledge milieu the same for firms with strategies S1, S2 and S3? In order to assess this additional issue, the analysis introduces the concept of knowledge potential for each location where a firm is established. From this we are able to conclude two things. First, the knowledge potential captures the probability and cost of integration of external and internal knowledge. Second, such a conjunction of internal and external knowledge sources shifts a firm's innovation and economic performance upwards.

In summary, this chapter has consulted existing literature to find convincing arguments and empirical findings that support the suggestion that adoption and innovation activities are similar in their reliance on skills in combining and integrating internal and external knowledge. The presentation adds to this knowledge by suggesting alternative ways of identifying a firm's internal and external knowledge, and ways of observing phenomena that reveal the conjunction of internal and external knowledge sources. The paper also provides examples of how to define and empirically measure firm performance.

One major suggestion is that a firm's persistent renewal efforts is a reliable indicator of the firm's internal knowledge, including innovation and adoption know-how. Combining this variable with a firm's external knowledge potential, the paper offers an explanation to the observed phenomenon that in each industry an almost invariant set of firm's perform far above the average firm in terms TFP growth, labor productivity and export performance. 


\section{REFERENCES}

Aghion, P., Bloom, N., Blundell, R. Griffith, R. and Howitt, P. (2005), Competitione and innovation: an inverted relationship, Quartely Journal of Economics, May 2005: 701728

Almeida P, and Phene A (2012), Managing Knowledge Within and Outside the Multinational Corporation’. In Andersson M, Johansson B, Karlsson C and Lööf H (eds.), Innovation and Growth, From R\&D Strategies of Innovation Firms to Economy Wide Technological Change. Great Britian: Oxford University Press.

Almeida P, Kogut B. (1999), Localization of Knowledge and the Mobility of Engineers in Regional Networks. Management Science 45(7), 905-917.

Andersson M, Thulin P, (2011), Labor Mobility and Spatial Density, CESIS Working Paper Series No 248, Centre of Excellence for Science and Innovation Studies, Royal Institute of Technology, Stockholm

Andersson M, Johansson B (2012), Heterogenous Distributions of Firms Sustained by Innovation Dynamics - A Model with Empirical Illustrations and Analysis, Journal of Industry, Competition and Trade, 12:239-263

Andersson M, Gråsjö U(2009), Spatial dependence and the representation of space in empirical models, The Annals of Regional Science, Springer 43(1), 159-180.

Antonelli C (1989), A Failure-Inducement Model of Research and Development Expenditure, Journal of Economic Behavior and Organization 12,159-180

Antonelli, C., Crespi, F. and Scellato, G. (2012), Inside innovation persistence: New evidence from Italian micro-data, Structural Change and Economic Dynamics, 23:341-353

Antonelli, C. (2013), Knowledge governance, pecuniary knowledge externalities and total factor productivity growth, Economic Development Quarterly, 27:62-70

Antonelli, C., Crespi, F. and Scellato, G. (2013), Internal and external factors in innovation persistence, Economics of Innnovation and New Technology, 22:256-280

Barney J (1991), Firm Resources and Sustained Competitive Advantage, Journal of Management 17, 99-120.

Beckmann MJ (2000), Interurban Knowledge Networks. In Batten D (ed), Learning, Innovation and Urban Evolution, Kluwer Academic, London, 127-135.

Blundell R, Bond S. (1998), Initial Conditions and Moment Restrictions in Dynamic Panel Data Models, Journal of Econometrics 87,115-143

Cantwell J, Zhang F (2012), Knowledge Accession Strategies and the Spatial Organization of R\&D. In Andersson, M, Johansson, B, Karlsson, C and Lööf, H. (eds.), Innovation 
and Growth, From R\&D Strategies of Innovation Firms to Economy Wide

Technological Change. Great Britain: Oxford University Press.

Cefis E, Cicarelli M (2005), Profit Differential and Innovation, Economics of Innovation and new Technology, 14:43-61

Cohen WM (2010), Fifty Years of Empirical Studies of Innovative Activity and Performance. In Hall, B.H. and Rosenberg, N. (eds), Handbook of the Economics of Innovation, North-Holland, Elsevier, Amsterdam, 129-213

Cohen W, Levinthal D (1990), Absorptive capacity: A new perspective on learning and innovation, Administrative Science Quarterly 35 (1), 128-158

Crépon B, Duguet E, Mairesse (1998), Research, Innovation And Productivity: An Econometric Analysis At The Firm Level, Economics of Innovation and New technology 7(2), 115-158.

Crespi G, Criscuolo C, Haskel J, Slaughter M (2007), Productivity Growth, Knowledge Flows and Spillovers. CEP Discussion Papers dp0785.

Dosi G, Nelson RR (2010), Technical Change and Industrial Dynamics as Evolutionary Processes. In B. Hall and N. Rosenberg (eds.) The Economics of Innovation, Elsevier

Feldman M, Kogler D F (2010), Stylized facts in the geography of innovation. In BH. Hall and N. Rosenberg (eds.) The Economics of Innovation, Elsevier

Fedlman M, Audretch DB (1999), Innovation in Cities: Science-based Diversity, Specialization and Localized Competition, European Economic Review 43, 409-429

Geroski P (1998), An Applied Econometrician's View on Large Company Performance, Review of Industrial Organization, 13:271-294

Goolsbee A, and Klenow PJ (2002), Evidence on Learning and Network Externalities in the Diffusion of Home Computers," Journal of Law and Economics XLV, 317-344.

Griliches Z, Mairesse J (1995), Production functions: the search for identification, NBER.

Hall, B.H. (2011), Using productivity growth as an innovation indicator, Report for the High Level Panel on Measuring Innovation, DG Research,European Commission

Hall BH (2002), The Financing of Research and Development, Oxford Review of Economic Policy $18,35-48$

Heckscher E (1918), Svenska produktionsproblem (Swedish Production Problems), Bonniers, Stockholm

Hotelling H (1932), Edgworth's Taxation Paradox and the Nature of Demand and Supply Fuctions, Journal of Political Economy 40,577-616

Jacobs J (1969), The Economy of Cities. Random House, New York 
Jacobs J (1984), Cities and the Wealth of Nations. Random House, New York

Jaffe AB, Trajtenberg M, Henderson R (1993), Geographic Localization of Knowledge Spillovers as Evidenced by Panel Citations, The Quarterly Journal of Economics 108, $577-598$

Johansson, B., Johansson, S. and Wallin, T. (2014), Internal and external knowledge and introduction of export varieties, The World Economy, doi: 10.1111/twec.12161

Johansson, B., Lööf H (2008), Innovation Activities Explained by Firm Attributes and Location, Economics of Innovation and New Technology 16, 533-552

Johansson, B. and Klaesson, J. (2011), Agglomeration Dynamics of Business Services, Annals of Regional Science 47, 373-391

Krugman P (1991), Increasing Returns and Economic Geography, Journal of Political Economy 99(3), 483-99.

Lamorgese AR, Ottaviano IP (2006), Intercity Interactions: Evidence from the US. 2006 Meeting Papers 667. Society for Economic Dynamics.

Lychagin S, Pinkse J, Slade ME, Van Reenen, J (2010. Spillovers in Space: Does Geography Matter?, NBER Working Papers 16188, National Bureau of Economic Research

Lööf H, Johansson B, Anderson M, Carlsson C (2012), R\&D Strategy and Firm Performance. In Andersson, M, Johansson, B, Karlsson, C and Lööf, H. (eds.), Innovation and Growth, From R\&D Strategies of Innovation Firms to Economy Wide Technological Change. Great Britain: Oxford University Press

Lööf H, Nabavi P, Johansson B (2012), Innovation Efforts, Spillovers and Productivity: How can firms benefit from access to knowledge-intensive producer services? CESIS Working Papers Series No 283, Royal Institute of Technology, Stockholm

Lööf, H. and Johansson, B. (2012), R\&D Strategy, Metropolitan Externalities and Productivity, CESIS Working Paper Series No 313, Centre of Excellence for Science and Innovation Studies, Royal Institute of Technology, Stockholm

Lööf H, Nabavi P, Cook G, Johansson B (2014a), Learning-by-exporting and Innovation Strategies, Economics of Innovation and New Technology, forthcoming.

Lööf, H. and Nabavi, P. (2014b), Joint Impact of Innovation and Knowledge Spillovers on Productivity and Growth for Exporting Firms, The World Economy, forthcoming MacDonald JM (1985), R\&D and the Direction of Diversification, Review of Economics and Statistics 47:583-590 
Mairesse J, Robin S (2012), The Importance of Process and Product Innovation for French Manufacturing and Service Industries. In Andersson, M, Johansson, B, Karlsson, C and Lööf, H. (eds.), Innovation and Growth, From R\&D Strategies of Innovation Firms to Economy Wide Technological Change. Great Britain: Oxford University Press

Mansfield, E (1987), Price Indexes for R and D Inputs 1969-1983, Management Science $33(1)$

Martinsson G, Lööf H (2013), Financial Factors and Patents. In Andreas Pyka and Esben Sloth Andersen (eds.) Innovation, Organisation, Sustainability and Crises. Springer

Montgomery C, and Hariharan S (1991), Diversified Expansion in Large Estabished Firms, Journal of Economic Behavior and Organization 15,71-89

Moretti E (2004), Workers' Education, Spillovers, and Productivity: Evidence from PlantLevel Production Functions, American Economic Review 94 (3), 656-690

Nelson RR Winter S G (1982), An Evolutionary Theory of Economic Change, Cambridge, MA, Belknap Press

Peters, B. (2009), Persistence of innovation: Stylized fact and panel data evidence, Journal of Technology Transfer, 34:226-243

Phene A, Almeida P (2008), Innovation in Multinational Subsidiaries: The role of knowedge assimilation and subsidiary capabilities, Journal of International Business Studies 39, 901-919

Polanyi M (1966), The Tacit Dimension. Doubleday \& Company, New York.

Romer PM (1990), Endogenous Technological Change. Journal of Political Economy 98(5), 102

Salter WEG (1960), Productivity and Technical Change, Cambridge University Press, Cambridge

Schumpeter J (1934), The Theory of Economic Development, Cambridge, Mass: Harvard University Press

Simmie J (2003), Innovation and Urban Regions as National and International Nodes for Transfer and Sharing of Knowledge, Regional Studies 37, 607-620

Solow R (1957), Technical Change and the Aggregate Production Function, Review of Economics and Statistics 34,312-320

Stephan P (2002), Using Human Resource Data to Illuminate Innovation and Research Utilization. In Merrill, S. and McGeary, M. (eds), Using Human Resource Data to Track Innovation, National Academic Press, Washington DC 
Sutton, J. (1991), Sunk cost and market structure

Teece DJ (2010), Technological Innovation and the Theory of the Firm. In Hall, B. and Rosenberg, N. (eds), Handbook of the Economics of Innovation, Amsterdam: NorthHolland

Vega-Redondo F (2003), Economics and the Theory of Games, Cambridge, UK: Cambridge University Press

Weibull JW (1976), A Axiomatic Approach to the Measurement of Accessibility, Regional Science and Urban Economics 6,357-379 